Hollis, K. L. 1988. In search of a hypothetical construct: a reply to Guilford \& Dawkins. Anim. Behav., 36, 162163.

Lawrence, E. S. \& Allen, J. A. 1983. On the term 'search image'. Oikos, 40, 313-314.

Rescorla, R. A. 1988. Pavlovian conditioning: it's not what you think it is. Am. Psychol., 43, 151-160.

(Received 8 May 1988: MS. number: SC-445)

\section{The Priming and Retention of Agonistic Motivation in Male Siamese Fighting Fish, Betta splendens}

Fighting in pairs of male Siamese fighting fish is mediated in large part by the quality and duration of visual cues provided by each combatant to its opponent (Bronstein 1983a, b, 1984). Fighting, for instance, can be terminated rapidly if two fish become separated visually in the midst of combat (say, by one animal swimming behind a clump of plants; Bronstein 1981, 1983b). That is, male Betta appear to have only a brief within-fight memory for agonistic behaviour and the location of opponents. Agonistic memories of this type have occasionally been characterized in other vertebrate species e.g. by Peeke (1982), using sticklebacks, Gasterosteus aculeatus, and by Potegal \& tenBrink (1984), using hamsters, Mesocricetus auratus. The purpose of the current experiment was to explore the proactive time course for the priming of aggression by visual cues in male Betta. Aggression in this species is known to be facilitated by social stimulation occurring just prior to fighting (Hogan \& Bols 1980; Bronstein 1983a); however, I am unaware of any studies that have assessed the time course of such proactive influences on fighting.

Domesticated male Betta $(N=81)$ were purchased locally and maintained for 30-60 days in social isolation with lights on from 0800 to 2200 hours. Subjects were experimentally naive, fed 5 days per week, and had been pre-tested with a mirror to exclude those animals that failed to exhibit agonistic display (gill-cover erection). See Bronstein (1983a) for details of maintenance and pre-testing.

Testing took place in a rectangular glass tank $(41 \times 20 \times 27 \mathrm{~cm})$ with undyed gravel substrate and water $15 \mathrm{~cm}$ deep. Three sides of the test tank were covered with opaque cardboard; the front of the tank (4l cm long) remained uncovered to permit observation of the subjects. Also, a vertical approach line had been drawn on that front wall $7.62 \mathrm{~cm}$ from the left-hand side of the tank (the stimulus wall). Fish were tested in aged tap water not previously occupied by conspecifics; order of testing was randomized across groups; and animals were fed between 1 and $7 \mathrm{~h}$ prior to testing.

Animals were individually netted and placed in the test tank for 10 min of adaptation. Fish in the three independent experimental groups then received 15 min of aggression-eliciting stimulation from a highly aggressive conspecific male followed, after a retention interval $(0,1$, or $5 \mathrm{~min})$, by a second $15 \mathrm{~min}$ of stimulation from the same stimulus animal. Stimulation bouts were started by removing the opaque paper covering from the stimulus wall to reveal a clear plastic container ( 5 $\mathrm{cm}$ thick, and abutting and covering the entire outside of the stimulus wall) holding the conspecific male. Stimulation was terminated by re-covering the outside of the stimulus wall and subjects remained in the apparatus during their retention intervals. Control groups received the same handling as their respective experimental groups, except that controls were exposed only to the second of the agonistic encounters. Controls, therefore, received 10 min of adaptation, 15 min without stimulation, a retention interval (also without stimulation), and, finally, 15 min of aggression-eliciting cues. Stimulus animals always showed high levels of aggression and a composite attack score was computed for each subject during each 15 min of stimulation Attack was defined as the number of seconds spent by each animal with its eyes between the approach line and the stimulus wall while engaging in gillcover erection, biting, or lateral display (rapid sideto-side swimming with extended fins).

The experimental groups did not differ in attack duration during their initial exposure to the aggression-eliciting conspecific. Median attack durations varied only from 608 to $620 \mathrm{~s}$ among the three groups $\left(\chi^{2}{ }_{2}=0 \cdot 0\right.$, Ns by median test, Siegel 1956 , pp. 179-184). This null finding supports the expectation of random subject assignment among groups. However, as seen in Table I, and relative to controls, attack durations during experimental animals' second stimulus exposures were inversely proportional to the time intervening between bouts of stimulation. Attack scores of experimental groups were reliably higher than those of controls when the two bouts of agonistic stimulation were separated by 1 min or less $(P s<0.02)$. With a retention interval of $5 \mathrm{~min}$, however, no difference between experimental and control conditions was noted.

These findings, involving the deliberate elimination of pheromones that might influence fighting (Noakes 1982), confirm the impression of the rapid offset of aggressive motivation during fights between pairs of male Betta. The tendency to fight wanes reliably after $5 \mathrm{~min}$ without conspecific visual stimulation. The memory that so rapidly 
Table I. Median attack duration (s)

\begin{tabular}{lccc}
\hline \multicolumn{4}{c}{ Retention intervals (min) } \\
\cline { 2 - 4 } & 0 & 1 & 5 \\
\hline Experimental groups & & \\
$N$ & 18 & 12 & 12 \\
Median & 900 & 838 & 643 \\
Range & $170-900$ & $438-900$ & $90-896$ \\
Control groups & & \\
$N$ & 15 & 12 & 12 \\
Median & 728 & 307 & 481 \\
Range & $40-900$ & $114-889$ & $123-898$ \\
$U$-values & $67^{*}$ & $28 *$ & 62 \\
\hline
\end{tabular}

$U$-values refer to the two-tailed differences between pairs of groups within a retention interval: ${ }^{*} P<0 \cdot 02$.

becomes unavailable to the fish may have an associative component (cf. Bronstein 1986), but the current findings could also reflect the quick deterioration of a non-associative warm-up process.

This research was supported by grants from the National Institute of Mental Health, the Rackham Foundation and the Faculty Development Committee of the University of Michigan-Flint. This paper was prepared at the University of Wales, Swansea, where the author was on sabbatical leave in the laboratory of Professor Paul F. Brain.

Department of Psychology,

University of Michigan-Flint,

Flint, Michigan 48502-2186, U.S.A.

\section{References}

Bronstein, P. M. 1981. Commitments to aggression and to nest sites in male Betta splendens. J. comp. physiol. Psychol., 95, 436-449.

Bronstein, P. M. 1983a. Onset of combat in male Betta splendens. J. comp. Psychol., 97, 135-139.

Bronstein, P. M. 1983b. Agonistic sequences and the assessment of opponents in male Betta splendens. Am. J. Psychol., 96, 163-177.

Bronstein, P. M. 1984. A confound in the application of fixed-ratio schedules to the social behavior of male Siamese fighting fish. Bull. Psychon. Soc., 22, 484-487.

Bronstein, P. M. 1986. Socially mediated learning in male Betta splendens. J. comp. Psychol., 100, 279-284.

Hogan, J. A. \& Bols, R. J. 1980. Priming of aggressive motivation in Betta splendens. Anim. Behav., 28, 135 142.

Noakes, D. L. G. 1982. Effects of chemical signals in Betta splendens. Revue can. Biol. Exp., 41, 217-219.
Peeke, H. V. S. 1982. Stimulus- and motivation-specific sensitization and redirection and aggression in threcspined stickleback (Gasterosteus aculeatus). J. (omp) physiol. Psychol., 96, 816-822.

Potegal, M. \& tenBrink, L. 1984. Behavior of attackprimed and attack-satiated female golden hamsters (Mesocricetus auratus). J. comp. Psychol., 98, 66-75.

Siegel, S. 1956. Nonparametric Statistics. New York: McGraw-Hill.

(Received 19 March 1988; revised 18 May 1988; MS. number: $S(-439$ )

\section{Effects of a Postpartum Separation on Maternal Responses in Primiparous and Multiparous Cows}

In ungulates, if contact between the mother and her newborn young is delayed just after birth, her subsequent maternal behaviour can be impaired (goats, Capra hirca; Klopfer et al. 1964; Smith et al. 1966; sheep, Ovis aries: Poindron et al. 1979; cattle, Bos taurus: Le Neindre \& Garel 1976; Hudson \& Mullord 1977). The short period following birth is described as a 'critical' or 'sensitive' period. However, previous maternal experience can increase the maintenance of maternal behaviour in domestic goats (Lickliter 1982). Furthermore, in contrast to rodents (Rosenblatt et al. 1979), sensitive periods in ungulates are complicated by the rapid establishment of a selective bond (Hersher et al. 1963a, b) Thus, in the present study we investigated the possible influence of maternal experience in cattle on the fading of maternal responses after separation from the calf, and the acceptance of an alien young.

We used 37 primiparous $(N=19)$ or multiparous $(N=18$, mean number of previous parental cycles $=5 \cdot 8$ ) Salers beef cows. The calf was removed from its mother immediately after birth and kept in straw-bedded pens separated from other calves. There were no signs of distress in calves separated from their mother immediately after birth. The cow had no contact with any calf except at the time of the brief calf presentation. The test presentation involved bringing first an alien calf (mean age $=5$ days) and then the cow's own calf to the cow for $5 \mathrm{~min}$. Numbers of head butts, licks and threats, and time spent licking were measured. No aggressive responses were sufficiently severe to warrant termination of behavioural tests. This test was carried out within either $0 \cdot 5-1 \mathrm{~h}$ of birth $(N=17)$ or $24-35 \mathrm{~h}$ of birth $(N=20)$. After testing the calves stayed with their mother until weaning. The results are summarized in Table I.

In contrast to results on dairy cows (Selman et al. 1970; Le Neindre \& Garel 1976), none of the cows 